\title{
Trans-Tasman Sea larval transport: Is Australia a source for New Zealand rock lobsters?
}

\author{
Stephen M. Chiswell ${ }^{1, *}$, John Wilkin ${ }^{2}$, John D. Booth ${ }^{1}$, Basil Stanton ${ }^{1}$ \\ ${ }^{1}$ National Institute of Water and Atmospheric Research, PO Box 14-901, Wellington, New Zealand \\ ${ }^{2}$ Institute of Marine \& Coastal Sciences, Rutgers University, 71 Dudley Road, New Brunswick, New Jersey 08901-8521, USA
}

\begin{abstract}
Two species of rock lobster (Palinuridae) are commonly found in coastal waters around both New Zealand and Australia. Both species have a relatively long larval phase, which raises the question of how populations can be maintained in regions where the mean flow advects larvae away from the coast. Previous work shows that Jasus edwardsii is genetically indistinguishable between Australia and New Zealand, whereas Sagmariasus verreauxi may be genetically different between the 2 countries. Satellite altimeter data are used here to test the hypothesis that Australia acts as a source of larvae for some New Zealand populations, and to investigate if there is a physical mechanism for the apparent lack of gene flow for $S$. verreauxi. A Lagrangian approach is used in which the western Tasman Sea is seeded with numerical drifters to build up a statistical summary of the likely distribution of larval trajectories. Ignoring biological factors, about $9 \%$ of $J$. edwardsii and about $2 \%$ of $S$. verreauxi larvae might be expected to arrive in New Zealand waters within their respective larval lifetimes. An order-of-magnitude estimate shows that even with extremely high mortality, these rates are high enough for trans-Tasman larval flow to contribute to and possibly maintain some New Zealand populations. Larval flow across the Tasman Sea should be sufficient to maintain transTasman genetic homogeneity in both species. We suggest that 1 reason that $S$. verreauxi may not be genetically homogenous is that in order to arrive in New Zealand within 1 larval lifetime, they have to cross the Tasman Sea north of the productive Subtropical Front where there is not enough prey to sustain them.
\end{abstract}

KEY WORDS: Lobster larvae $\cdot$ Tasman Sea $\cdot$ Modelling

\section{INTRODUCTION}

Two species of rock lobster (Palinuridae) are commonly found in coastal waters around New Zealand. The most abundant of these, Jasus edwardsii (red rock lobster), is found around the entire country, with highest adult populations along the east coast of North Island, and the southwest of South Island from Fiordland to Stewart Island (Fig. 1). Annual landings of $J$. edwardsii are about $2500 \mathrm{t}$ (Annala et al. 2001). The other species, Sagmariasus verreauxi (packhorse rock lobster), is of much less commercial importance, and is more restricted in location, occurring mainly on the east coast of North Island (Booth 1986).

*Email: s.chiswell@niwa.cri.nz
Jasus edwardsii may well have the longest-lived larval phase (phyllosoma) of any rock lobster. Phyllosomas are transparent leaf-like plankters whose body shape appears well-suited for drifting. The duration of the $J$. edwardsii phyllosoma stage in nature has been estimated to be between 12 to 24 mo (Booth \& Phillips 1994). Phyllosomas are generally regarded as having little or no directed horizontal swimming ability, and this long larval phase raises the question of how any population can be maintained in regions where the mean flow advects larvae away from the coast. It has been reasonably well established from both direct observation and modelling that $J$. edwardsii populations off the east coast of New Zealand's North Island are maintained by the presence of 1 or more large 


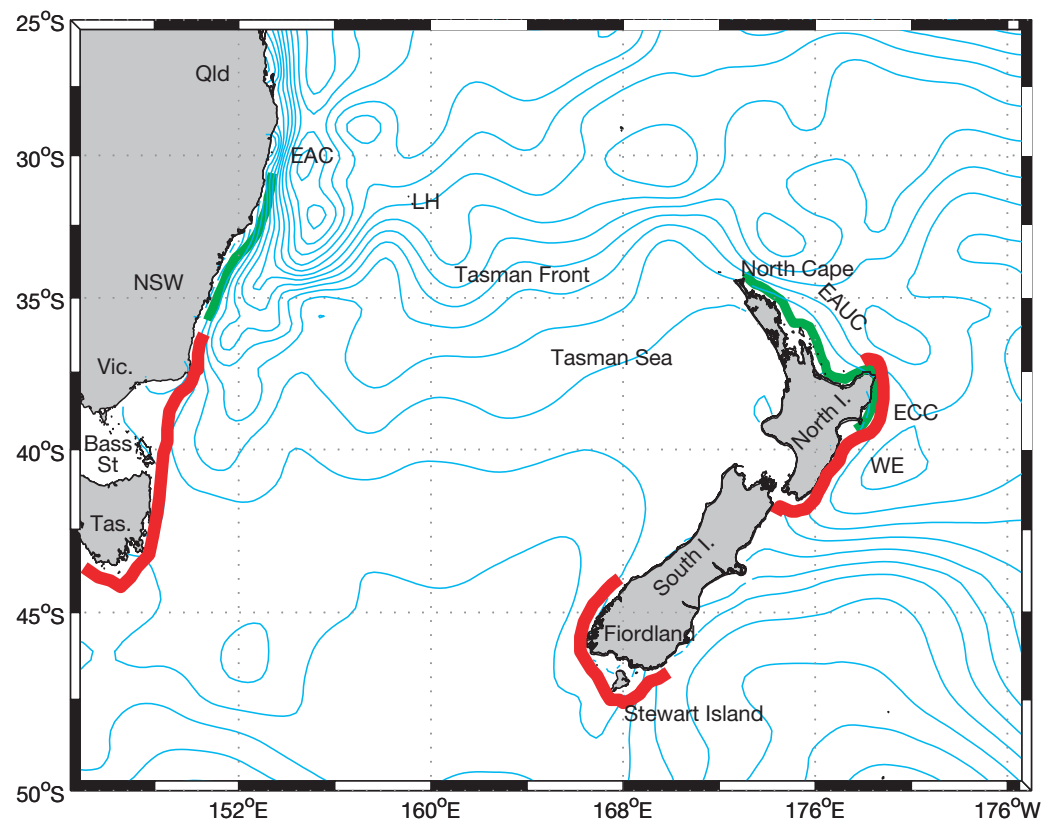

Fig. 1. Map of the Tasman Sea showing locations mentioned in the text. Thick red lines show the approximate regions of higher standing stocks of Jasus edwardsii in New Zealand and Australia. Thick green lines show the approximate regions of higher standing stocks of Sagmariasus verreauxi in both countries. Contours are of mean dynamic height, $\Delta \bar{D}_{0 / 2000}$ (dynamic $\mathrm{m}$ ) from CARS climatology (see text). The East Australian Current (EAC) can be seen as a region of high spatial gradient in dynamic height off the east Australian coast. This current crosses the Tasman Sea at about $35^{\circ} \mathrm{S}$, where it is commonly known as the Tasman Front. Also shown are the major currents and eddies around New Zealand: EAUC = East Auckland Current, $\mathrm{ECC}=$ East Cape Current, WE = Wairarapa Eddy. Australian states of Tasmania (Tas.), Victoria (Vic.), New South Wales (NSW), and Queensland (Qld) and Lord Howe Island (LH) are also labelled

(approximately $200 \mathrm{~km}$ diameter) permanent eddies, such as the Wairarapa Eddy shown in Fig. 1 (Booth \& Stewart 1992, Chiswell \& Booth 1999). These eddies appear to retain phyllosomas long enough for them to develop into the post-larval puerulus stage, and then swim back to the coast.

There is a substantial fishery for Jasus edwardsii on the southwest coast of South Island, and the presence of these South Island populations, away from the influence of the east coast eddies, raises the question of how they are maintained. Mean dynamic height field (Fig. 1) shows no evidence of permanent eddies off the west coast of New Zealand that could entrain phyllosomas, so it appears that these populations are maintained by a mechanism other than entrainment of phyllosomas offshore.

It has been suggested that Australia acts as a source of Jasus edwardsii larvae, and that phyllosomas drift across the Tasman Sea before metamorphosing near the west coast of New Zealand (Booth et al. 1990, Booth \& Ovenden 2000). Large breeding stocks of $J$. edwardsii are found in Australia along the southern New South Wales, Victorian, Tasmanian, and South Australian coasts (Phillips et al. 2000) and these could provide a source for New Zealand west coast populations. Evidence supporting this theory is that mid- and late-stage J. edwardsii phyllosomas have been found all the way across the Tasman Sea (Booth et al. 1990, Booth \& Ovenden 2000). In addition, settlement of pueruli occurs along the west coast of New Zealand's South Island, with highest levels recorded in southern Fiordland (Booth \& Breen 1992).

Analysis of mitochondrial DNA shows that Jasus edwardsii populations are genetically indistinguishable between Australia and New Zealand (Ovenden et al. 1992). This suggests either that populations were isolated too recently to allow genetic divergence, or that there is sustained gene flow between them. Sustained gene flow would be additional evidence for trans-Tasman larval drift.

Sagmariasus verreauxi appears to have a slightly different life cycle (Booth 1986). The duration of the phyllosoma phase in $S$. verreauxi is less well estimated but is thought to be between 8 and 12 mo (Booth 1986). This species appears to have evolved a life cycle that may not be so dependent on local eddy retention. The main breeding population for this species is in the extreme north near North Cape. Phyllosomas appear to drift southwards in the East Auckland Current, and settlement occurs well south of the breeding population. Most juveniles then migrate north towards North Cape near where they mature and breed.

Sagmariasus verreauxi also occurs in Australia, along the New South Wales coast (Fig. 1), but unlike Jasus edwardsii, S. verreauxi may be genetically different between the 2 countries. Preliminary work on mitochondrial DNA has found differences in several markers, suggesting that the 2 populations are reproductively isolated (Brasher et al. 1992).

There are several possible reasons why these 2 species should show such different genetic relationships across the Tasman Sea. It could be that transit times across it fall within the larval life lifetime for Jasus edwardsii, but are too long to allow Sagmariasus verreauxi larvae to successfully reach New Zealand. Alternatively, since $S$. verreauxi is a warmer-water species, and breeding $S$. verreauxi occur mainly along the east coast of Australia between 30 and $33^{\circ} \mathrm{S}$ (Phillips et al. 2000), it could be that larvae entering 
the Tasman Sea this far north simply do not reach New Zealand.

The aims of this article are to investigate these issues, and in particular to address the following questions:

(1) Does larval supply from Australia maintain west coast New Zealand Jasus edwardsii-i.e. do transit times for phyllosomas drifting across the Tasman Sea fall within known bounds for larval lifetime? If so, can we predict likely sources of larvae for New Zealand settlement?

(2) Is there an oceanographic reason why $J$. edwardsii and Sagmariasus verreauxi should show different genetic relationships between New Zealand and Australia?

Few data exist to answer such questions. A limited number of surface drifters (Fig. 2) gives a tantalising glimpse of travel times ranging from several months to several years. Although none of the drifters shown in Fig. 2 actually reach the west coast of South Island, the transit times are often within the larval lifetime of Jasus edwardsii, which lends support to the idea that Australia is a source of South Island west coast populations.

Satellite altimeter-derived measurements of surface current were used to model potential larval trajectories across the Tasman Sea. A Lagrangian approach was employed in which the Tasman Sea was seeded with a number of numerical drifters, where the tracks of individual drifters were determined from the time-varying

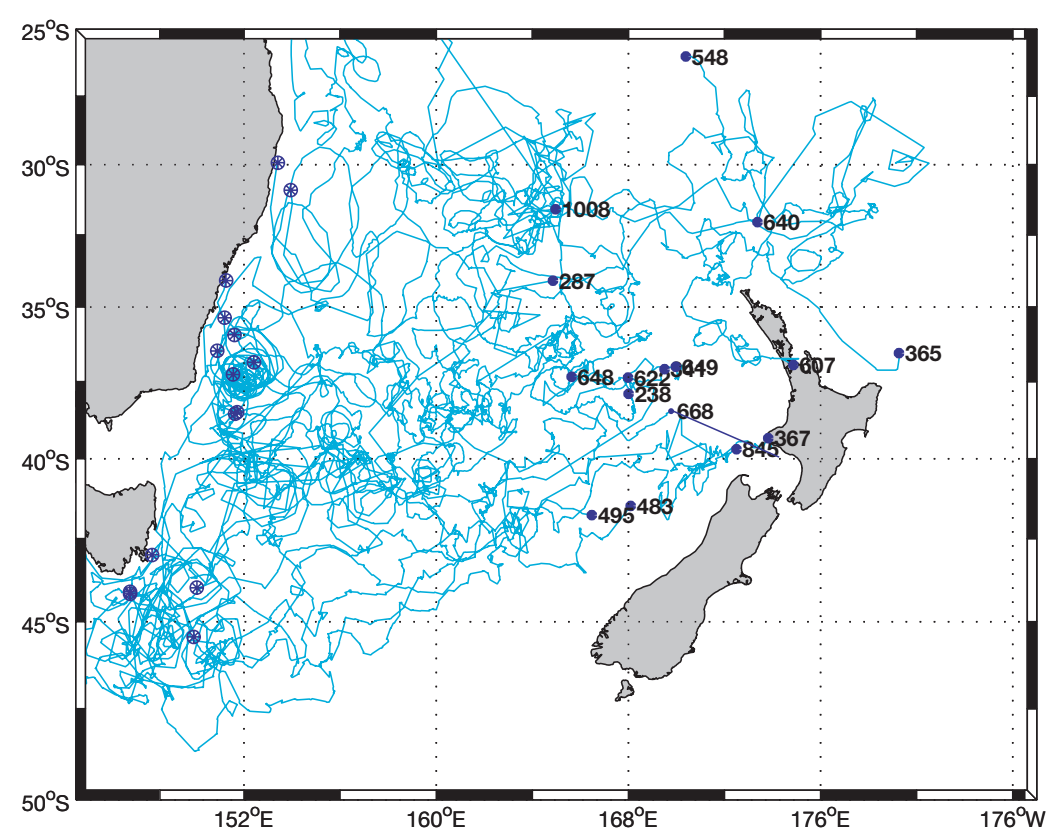

Fig. 2. Trajectories from satellite-tracked surface-drifting buoys that were released near the Australian coast and crossed as far as $164^{\circ} \mathrm{E}$. Release locations are shown as starred circles. Crossing time in days is marked near the last recorded location of each buoy current field. By seeding the sea every few days, a statistical summary of the likely distribution of trajectories for each source location could be built up. This approach differs from the Eulerian approach used by Chiswell \& Booth (1999) because it is more suited to the investigation of individual drifter tracks and their travel times. The drifters are treated as being completely passive, and mortality and most other biological aspects are ignored.

The surface wind-driven transport (i.e. the Ekman transport: e.g. Pond \& Pickard 1978) may be important in larval transport. The Tasman Sea is bordered to the south by prevailing westerlies and to the north by prevailing easterlies. In both cases, the implied Ekman transport is towards the middle latitudes of the Tasman Sea, so that winds are likely to concentrate larvae in surface waters towards the centre of the sea. Although the Ekman transport can be computed relatively easily, it is not obvious how much this affects phyllosoma distributions. There is undoubtedly diel migration of phyllosomas as they rise to the surface at night to feed, and sink to depths during the day to escape predation. The exact pattern of diel migration is not known, although evidence for shallow water palinurids worldwide is that they do not sink much deeper than about $200 \mathrm{~m}$ (Booth 2003). We had no good estimate of how much of the phyllosoma life phase is spent in the Ekman layer (typically 30 to $50 \mathrm{~m}$ ). Thus, we performed 2 sets of simulations. The first set ignored the wind-driven component, and calculated trajectories assuming larvae drift according to the surface geostrophic currents. The second set assumed that the larvae spend one-third of their lives in the Ekman layer.

Validation of the satellite-derived currents was largely impractical here because of the lack of independent direct measurements of the circulation within the Tasman Sea, and to some extent, we relied on extensive treatment elsewhere (e.g. Blayo et al. 1997). However, we did compare the buoy data seen in Fig. 2 with modelled currents.

Apart from the issue of how well ocean currents can be derived from altimeter measurements, there are several assumptions implicit in this work. One is that larvae behave as passive drifters with respect to horizontal transport. This is a common assumption in the treatment of larval dispersal (e.g. Black 1994), and there is little reason to believe phyllosomas behave otherwise, at least during the early part of their development. However, Chiswell \& Booth (1999) suggest that Jasus edwardsii phyllosoma may exhibit directed swimming towards the 
coast during the last few weeks of their development. There is not enough specific information on this behaviour to warrant incorporating it in this study, but we note that if it occurs, it may aid in increasing settlement rates of pueruli.

\section{MATERIALS AND METHODS}

Simulations. The United States-French TOPEX/ Poseidon (T/P) satellite altimeter measures sea level along the same path every 9.9156 d (Fu et al. 1994), and is generally considered to provide sea level accurate to a few cm (e.g. Mitchum 1994). Similarly, ERS-1 and -2 satellites launched by the European Space Agency carry a radar altimeter, although the ground path characteristics of the satellites differ from the T/P instrument. The data product used here was the AVISO ‘Maps of Sea Level Anomaly' (MSLA) provided by AVISO/Altimetry, Space Oceanography Division, France. Daily maps of sea level anomaly on a $0.25^{\circ}$ latitude by $0.25^{\circ}$ longitude grid were derived from merged T/P and ERS satellite data.

Because of uncertainties in the geoid, altimeter data are generally considered to be variations about mean sea level, and one needs a mean dynamic height field to add to the anomalies in order to obtain the timevarying circulation. Here, mean dynamic height was obtained from CARS (formerly 'Climatology of Australasian Regional Seas') provided by CSIRO (Commonwealth Scientific \& Industrial Research Organisation), Australia (Dunn \& Ridgway 2002, Ridgway et al. 2002). CARS is an atlas derived from 2 major datasets: the National Oceanographic Data Center (NODC) World Ocean Atlas 1998 hydrographic data, and a CSIRO archive of Australian hydrographic data. CARS is available via the web in netCDF file format.

For the purposes of this analysis, sea surface height from the AVISO data was assumed to be equivalent to dynamic height, and added to the CARS mean field to obtain the time-varying fields. Surface zonal $(u)$ and meridional $(v)$ currents were computed from the time varying dynamic height fields assuming geostrophy:

$$
u=-\frac{10}{f} \frac{\partial}{\partial y} \Delta D_{0 / 2000} \quad \text { or } \quad v=\frac{10}{f} \frac{\partial}{\partial x} \Delta D_{0 / 2000}
$$

where $\Delta D_{0 / 2000}$ is the time-varying dynamic height and $f$ is the Coriolis paramter.

The wind-driven Ekman layer was estimated using the NCEP (National Centers for Environmental Prediction) daily reanalysis of wind-stress. Estimating Ekman layer velocities from time-varying wind-stress is not entirely straightforward. Pollard \& Millard (1970) suggest integrating the equations of motion for a wind-stress uniformly distributed over the mixed layer, but even this simplification of the dynamics requires knowledge of the mixed layer depth which we do not have. Here, we took the computationally more efficient route of assuming that the Ekman layer velocity was to the left of the wind-stress, and had a magnitude corresponding to $15 \%$ of the wind-stress (in SI units). For time-specific analyses, such an approach tends to produce Ekman velocities of approximately the correct magnitude, but slightly out of phase with the real wind-driven flow (it does not allow for 'spin-up' of the wind-driven layer). Given the uncertainties in the windstress reanalysis, and in how phyllosomas behave vertically, it was decided that a more complicated approach was not warranted.

Once the currents were obtained, trajectories were calculated using a Lagrangian approach with 4th order Runge-Kutta numerics (e.g. Kelly 1967). Time steps were determined by the CFL (Courant-FriedrichsLewy) condition. Geostrophic velocity fields were linearly interpolated between the $10 \mathrm{~d}$ values. Ekman transport was computed from the nearest daily windstress value. No explicit diffusion was added. Trajectory algorithms were set so that as soon as a numeric drifter hit land, it was considered dead and was removed.

Source locations (751) were set about $200 \mathrm{~km}$ offshore from the east coast of Australia (Fig. 3). Thus, the modelling implicitly assumes that all hatched phyllosomas get as far as $200 \mathrm{~km}$ off the coast, and that this transport is instantaneous. This distance offshore was required to avoid having the numeric drifters hitting the Australian coast in the intense eddy field associated with the East Australian Current (EAC). Even with this distance offshore some drifters hit the Australian coast and were removed. In effect this reduced the number of simulations since we ignored all trajectories that hit the Australian coast. This assumption had some impact on travel times both because we ignored the time taken to travel $200 \mathrm{~km}$ offshore, and because excluding drifters that hit Australia set a slight bias to those drifters that got out of the eddy field quickly.

In the with-wind simulations, we assumed that phyllosomas spend one-third of their time in the Ekman layer, and simulated this by using appropriately weighted currents.

One simulation was made using the mean flow. Ninety-four simulations were made both with and without wind, for the time-varying flows starting approximately every $10 \mathrm{~d}$ from January 1993 to August 1995. Each simulation was run for $5 \mathrm{yr}$. Even with $5 \mathrm{yr}$ runs, a small number of drifters remained within the Tasman Sea at the end of the runs. These were ignored for calculation of the histograms, but assumed to eventually hit New Zealand for calculation of transit time probabilities. 


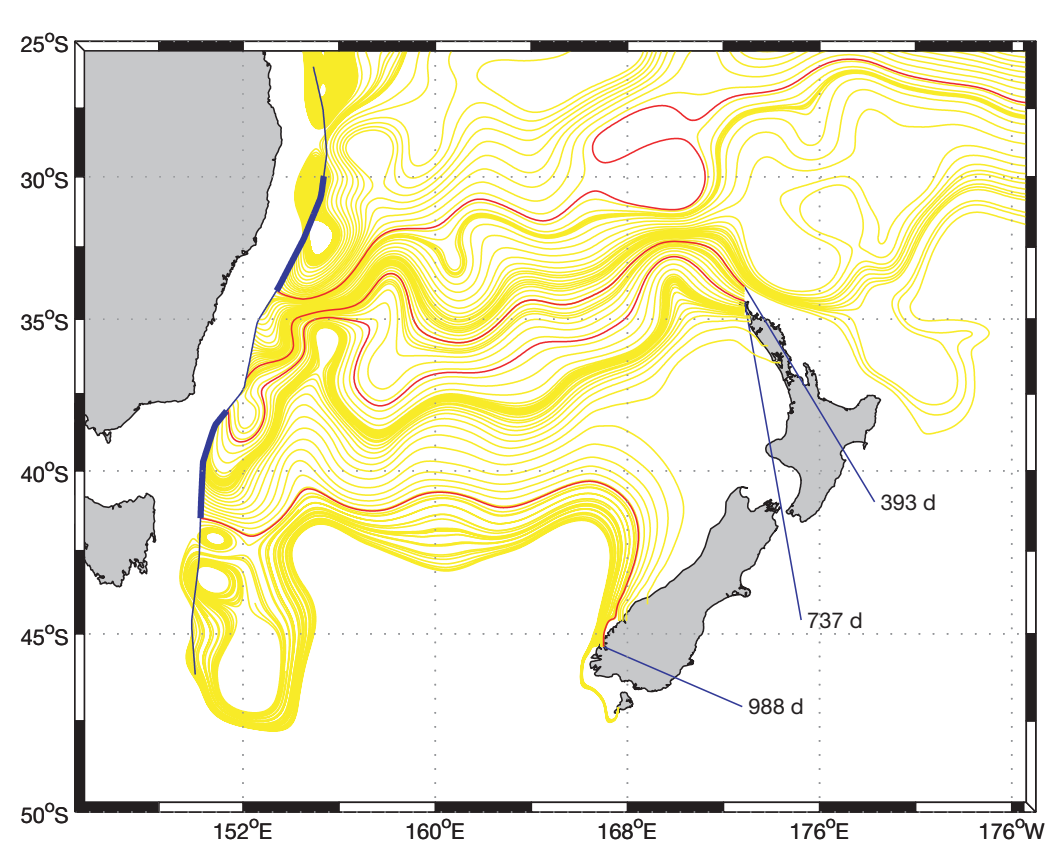

Fig. 3. Simulated tracks for drifters using the mean velocity field. The 751 release locations east of Australia are shown as a blue line. Source locations for Sagmariasus verreauxi and Jasus edwardsii are shown as thicker blue lines. Transit times in New Zealand for selected tracks are shown. Trajectories are in yellow. Red lines indicate main features of the mean flow

$0.06 \mathrm{~cm} \mathrm{~s}^{-1}$. The meridional velocities did not compare quite so well, but adding the Ekman velocity reduces the mean meridional velocity difference from 2.5 to $1.3 \mathrm{~cm}$ $\mathrm{s}^{-1}$. These results suggest that in the mean, observed buoy velocities are better matched by adding the Ekman velocities to the geostrophic velocities. This is perhaps not surprising (Sprintall et al. 1995) but it indirectly supports our Ekman dynamics simplification (the modelled buoy trajectories are better with it than without it).

Our computed meridional velocities show a stronger southerly component than the buoy velocities, and a comparison of Figs. 2 \& 3 shows that none of the buoys got entrained in the southward flow seen to the west of South Island in the mean CARS velocity (Fig. 3). There may be several reasons for this; one is that the surface buoys may have been affected by windage, perhaps due to significant drogue loss. Another reason is that the CARS mean velocity field may have been smearing out the southerly directed coastal currents found along the west coast of South Island. There is little that can be done to rectify this since we do not

Surface-drifting buoys. Surface-drifter data shown in Fig. 2 are from a variety of sources and are archived in the WOCE-SVP programme, which was developed as a partnership between the Atlantic Oceanographic and Meteorological Laboratory (AOML) in Miami and the Marine Environmental Data Service in Ottawa. The figure shows the trajectories of all satellite-tracked surface buoys that were released near Australia and crossed as far as $164^{\circ} \mathrm{E}$ (approximately half-way across the Tasman Sea).

For each buoy, $10 \mathrm{~d}$ mean buoy velocities were computed coinciding with the AVISO temporal sampling. Similarly, Ekman layer velocities and AVISO-derived geostrophic surface velocities were computed for each $10 \mathrm{~d}$ mean buoy location, allowing us to compare buoy velocity with the local geostrophic and Ekman layer velocities. Table 1 summarizes the mean velocities for the buoys east of $155^{\circ} \mathrm{E}$ (i.e. outside the intense eddy field off Tasmania).

The overall zonal buoy velocity was $3.1 \mathrm{~cm} \mathrm{~s}^{-1}$ to the east. The geostrophic zonal mean was $3.7 \mathrm{~cm} \mathrm{~s}^{-1}$, leading to a mean buoygeostrophic velocity difference of $-0.6 \mathrm{~cm} \mathrm{~s}^{-1}$. Adding the Ekman velocity reduces this difference to have sufficient data to adjust the mean field, so we simply note that if this was the case, then modelled trajectories may have had a bias towards arriving further south along South Island than in reality. Transit times may also have been a little longer than in reality.

Error analysis. One question that needs to be addressed is how accurately histograms and percentile travel times can be calculated from modelling such as this. Apart from the question of how well the currents can be computed from satellite data, we need to know if enough simulations were made to adequately describe the transit time histograms. The separation between initial source locations was $3 \mathrm{~km}$, and the separation in time between successive simulations was $10 \mathrm{~d}$. Both these parameters are likely to be much shorter than the dominant space- and timescales in the Tasman Sea. We estimate that the mesoscale eddy field probably has length scales of 10 s to 100 s of $\mathrm{km}$, and timescales of weeks to months rather than days.

Table 1. Comparison of satellite-derived velocities with surface buoy velocities east of $155^{\circ} \mathrm{E}$ in the Tasman Sea

\begin{tabular}{|lccccc|}
\hline & $\begin{array}{c}\text { Buoy } \\
\left(\mathrm{cm} \mathrm{s}^{-1}\right)\end{array}$ & $\begin{array}{c}\text { Geostrophic } \\
\left(\mathrm{cm} \mathrm{s}^{-1}\right)\end{array}$ & $\begin{array}{c}\text { Geostrophic }+ \\
\text { Ekman }\left(\mathrm{cm} \mathrm{s}^{-1}\right)\end{array}$ & $\begin{array}{c}\text { Buoy - geostrophic } \\
\left(\mathrm{cm} \mathrm{s}^{-1}\right)\end{array}$ & $\begin{array}{c}\text { Buoy- (geostrophic } \\
+ \text { Ekman) }\left(\mathrm{cm} \mathrm{s}^{-1}\right)\end{array}$ \\
\hline Zonal & 3.1 & 3.7 & 3.0 & -0.6 & 0.06 \\
Meridional & 0.8 & -1.7 & -0.5 & 2.5 & 1.3 \\
\hline
\end{tabular}


Thus, our system is over-sampled, and the trajectories cannot be considered independent. As an example of how this might affect error estimates, consider the histograms derived from $\sim 3000$ trajectories for the Jasus edwardsii no-wind case discussed later. The histogram of transit times has a median of $1099 \mathrm{~d}$ and a standard deviation of $376 \mathrm{~d}$. Although we do not expect transit times to be normally distributed, if the 3000 estimates of transit time were independent, the expected error in the estimate of the mean could be the standard deviation divided by the square root of 3000 , which is $6.8 \mathrm{~d}$. We do not know how over-sampled the system is, but if one assumes it is over-sampled by a factor of 50 (i.e. equivalent to a source spacing of $30 \mathrm{~km}$ and a reseeding interval of $50 \mathrm{~d}$ ), the error in the mean becomes $48 \mathrm{~d}$. Given the uncertainties in how well over-sampled the simulations are, we did not perform a formal error estimate for each histogram. Instead, somewhat arbitrarily, we suggest that the standard errors in the median travel time are likely to be close to $48 \mathrm{~d}$.

\section{RESULTS}

The 751 source locations spanned from 46 to $26^{\circ} \mathrm{S}$. From these, 2 groups were selected to represent source locations which we deemed to be representative of the actual locations of the breeding stock for each species (Fig. 3). The source of Sagmariasus verreauxi was chosen to be between 34 and $30^{\circ} \mathrm{S}$. The source of Jasus edwardsii was chosen to be from 41.5 to $38^{\circ} \mathrm{S}$.

\section{Mean flow}

Travel times across the Tasman Sea are principally controlled by the mean currents, which are determined here from the CARS mean field. This field is a climatology based on historic temperature and salinity measurements made in the Australia and New Zealand region. Such historic measurements are notoriously sparse, particularly offshore from either country, and to the south of the region. In parts, therefore, the mean climatology is based on few direct measurements, and may have considerable error. As a first step in this analysis, we present results based on the mean flow alone.

Mean dynamic height of the surface relative to 2000 dbar, $\Delta \bar{D}_{0 / 2000}$, from CARS (Fig. 1) illustrates the main features of flow in the Tasman Sea. The EAC appears along the Australian coast, and at about $35^{\circ} \mathrm{S}$ turns into a relatively broad eastward flow, known as the Tasman Front (e.g. Stanton 1981). The broad eastward drift across the Tasman Sea is bordered to the south by the Subtropical and Subantarctic Fronts (STF and SAF, respectively) - although in this mean, they appear diffuse and coalesced.

Trajectories calculated from the mean currents are shown in Fig. 3. Four trajectories shown in red emphasize the main features of the mean flow. Two trajectories show the northern- and southernmost trajectories from the Jasus edwardsii source. These have transit times of 737 and $988 \mathrm{~d}$, respectively. The trajectory from the southernmost Sagmariasus verreauxi source shows that all $S$. verreauxi phyllosomas would pass to the north of New Zealand. Fastest travel time across the Tasman Sea is for a trajectory within the core of the Tasman Front, and has a transit time of 393 d. This trajectory passes about $50 \mathrm{~km}$ north of North Cape.

Based on the mean field alone, it is difficult to see how trans-Tasman larval migration occurs for either species. For example, larvae hatching from the largest east coast Australian stocks of Jasus edwardsii, near Bass St, would take 2 to 3 yr to cross the Tasman Sea. Similarly, based on the mean field alone, it would appear that Sagmariasus verreauxi are unlikely to make it to New Zealand because their habitat is too far north.

\section{Time-varying flow}

Simulated trajectories and histograms of transit times from the runs made with the time-varying flow are shown in Fig. 4. The results show simulations made both with and without the effects of adding the Ekman wind-driven transport. Statistics of the arrivals are summarised by the median transit time, and 2 percentile numbers. The 1st percentile number is the percentage of all releases that arrive in New Zealand (in calculating this number, we have excluded all drifters that hit the Australian coast and were removed from the simulations, but retained drifters still in the Tasman Sea at the end of $5 \mathrm{yr}$ ). The 2 nd percentile is the percentage of all transit times that fall within 1 larval lifetime for the species under consideration. For Jasus edwardsii, this is taken to be $2 \mathrm{yr}$, and for Sagmariasus verreauxi, 1 yr.

\section{Jasus edwardsii}

As one would expect, the main effect of adding the time-varying flow to the mean is to widen the distribution of tracks, and to broaden the histogram of transit times compared with simulations made using the mean flow alone. The median transit time of $1099 \mathrm{~d}$ for the runs with no winds is about the same as the median time for the mean flow simulations. About $64 \%$ of releases from Bass St arrive in New Zealand waters, 
A) Sagmariasus verreauxi
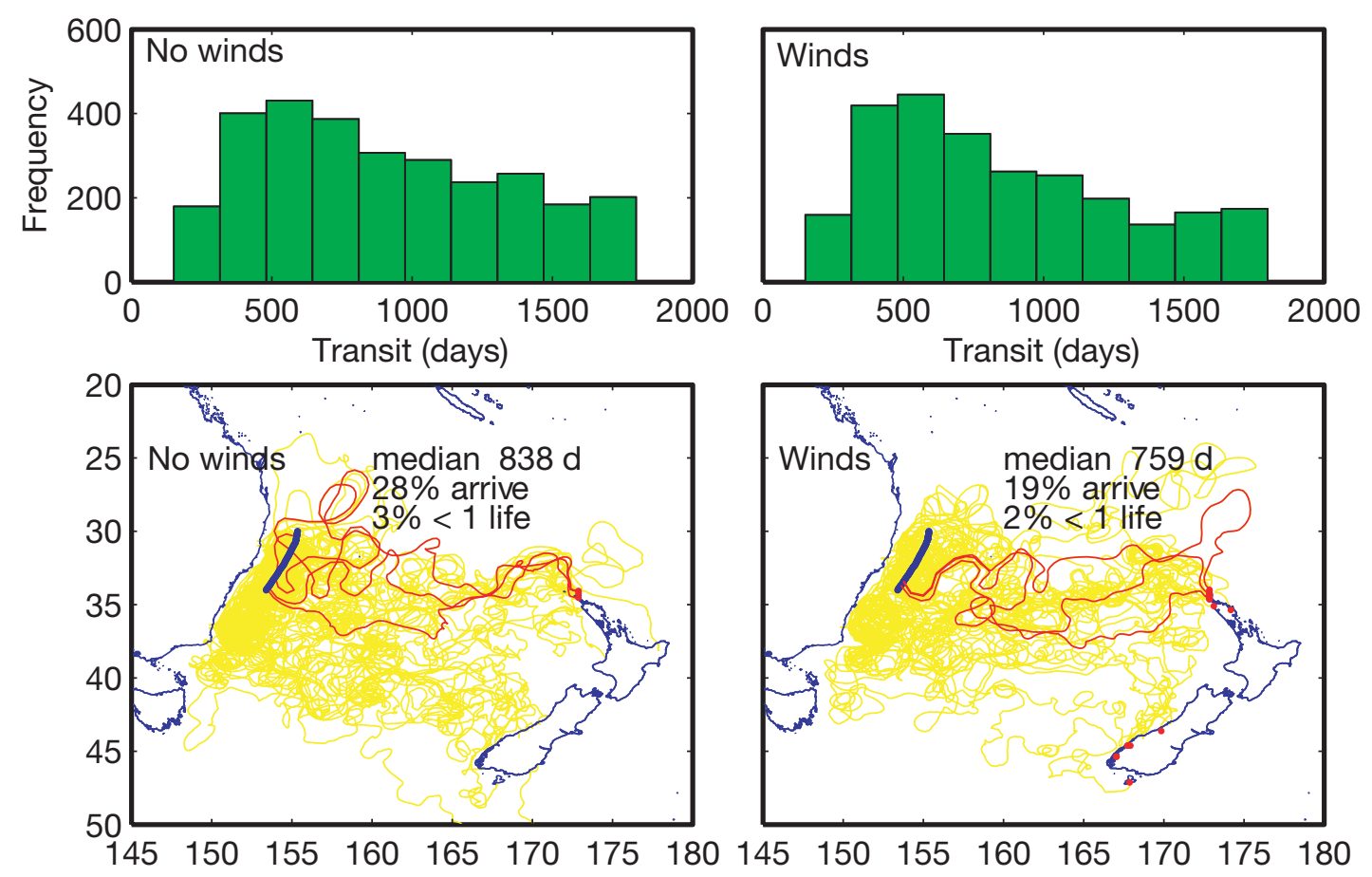

\section{B) Jasus edwardsii}
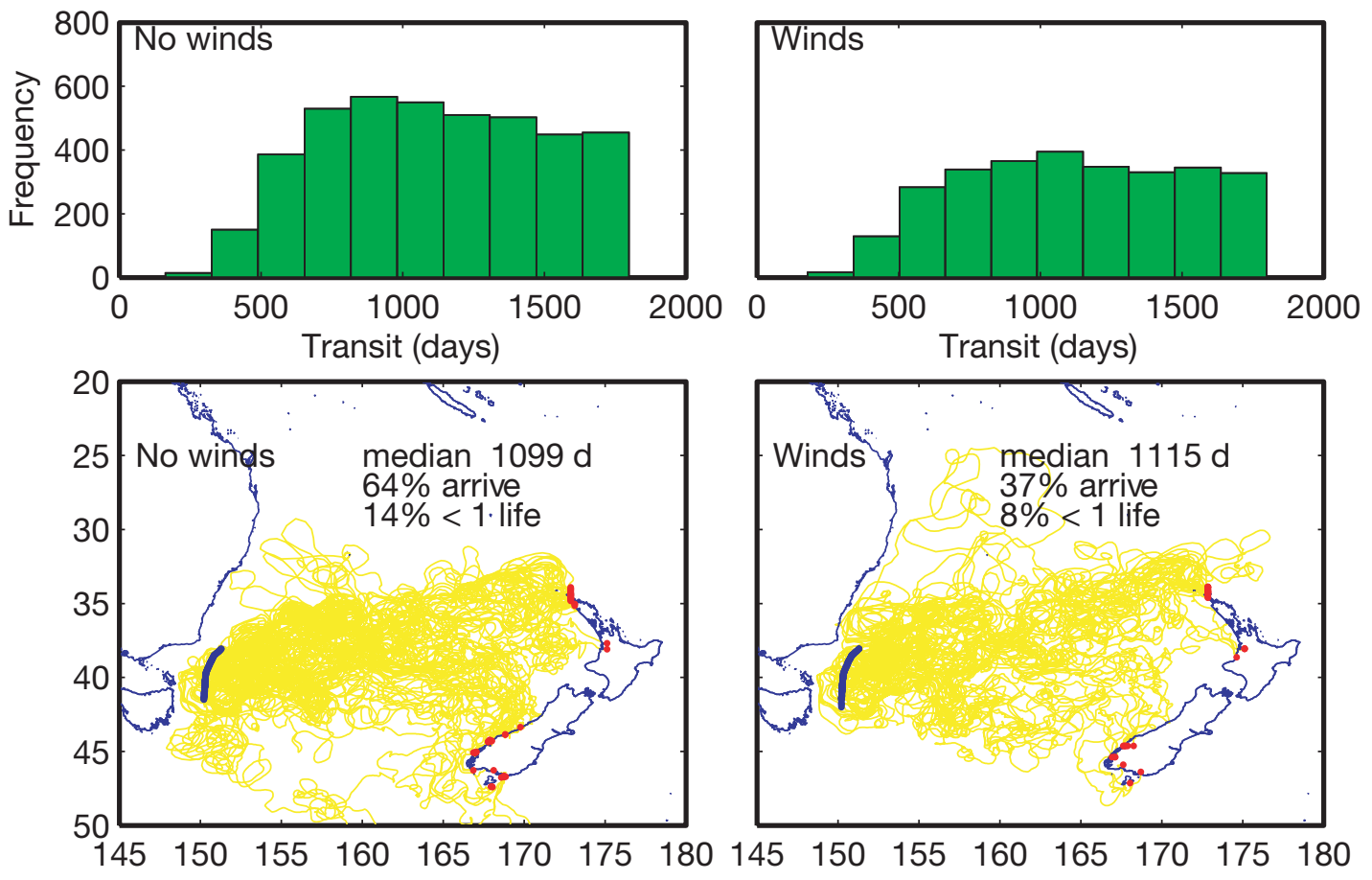

Fig. 4. Histograms of trans-Tasman transit times and selected tracks for numerical simulations (A) for Sagmariasus verreauxi. Left-hand panels show results for runs made without winds, right-hand panels show results for runs made including winds (see text). Only those tracks that arrive in New Zealand are shown. Blue lines show release locations, red dots show arrival locations. For these runs, 1 larval lifetime is taken to be 1 yr. (B) as in (A), but for Jasus edwardsii. For these runs, 1 larval lifetime is taken to be $2 \mathrm{yr}$ 
and about $14 \%$ of released phyllosomas arrive in New Zealand in less than $2 \mathrm{yr}$.

Prevailing winds in the Tasman Sea are from the west or south west. These winds have an Ekman component directed to the north or northwest so that the main effect of adding the winds to the simulations is to shift the latitudinal spread of the tracks north, especially to the south of $45^{\circ} \mathrm{S}$, and to increase the median transit time to $1115 \mathrm{~d}$. The number of arrivals reduces because more drifters pass north of New Zealand (not shown). About $37 \%$ of releases arrive in New Zealand waters, and about $8 \%$ of released larvae arrive in less than 2 yr.

\section{Sagmariasus verreauxi}

The Sagmariasus verreauxi source region is between 34 and $30^{\circ} \mathrm{S}$. None of the mean trajectories from this far north arrived in New Zealand (Fig. 3). However, when the time-varying fields are added, about $28 \%$ of trajectories reach New Zealand waters. Most arrivals are in the north of North Island, but some are as far south as Fiordland. The median transit time is $838 \mathrm{~d}$, and $3 \%$ of released drifters take less than $1 \mathrm{yr}$ to cross the Tasman Sea. When the winds are added, the median transit time decreases to $759 \mathrm{~d}$, and $2 \%$ of larvae take less than 1 yr to cross the sea.

Trajectories plotted in red are those where transit times were less than $1 \mathrm{yr}$, and show that only those drifters that get entrained in the Tasman Front cross the sea within 1 larval lifetime for Sagmariasus verreauxi. Compared to Jasus edwardsii, S. verreauxi larvae have about half the chance of arriving in New Zealand, but of those that do, median travel times are shorter, reflecting the fact that more of these larvae enter the relatively fast-moving Tasman Front.

\section{DISCUSSION}

Sagmariasus verreauxi and Jasus edwardsii larval lifetimes are approximately 1 and 2 yr, respectively. If we assume that the simulations incorporating winds are the most realistic, then with these timescales, and ignoring mortality and other biological factors, about $8 \%$ of $J$. edwardsii and about $2 \%$ of $S$. verreauxi phyllosomas hatched off Australia might be expected to arrive in New Zealand within their respective larval lifetime (Table 2). The shorter larval lifetime of $S$. verreauxi is, to some extent, compensated for by the fact that these animals are more likely to get entrained in the relatively fast-moving Tas- man Front, whereas J. edwardsii are more likely to drift more slowly in the southern Tasman Sea. Ignoring the Ekman transport in the simulations changes the spatial patterns of the trajectories but does not materially affect these percentiles. Thus our choice of the relative time spent in the Ekman layers (one-third) does not critically affect the conclusions.

Does larval supply from Australia maintain Jasus edwardsii on the west coast of New Zealand? A complete answer to this question is well beyond the scope of this article, since it depends, among other things, on the relative abundance of Australian and New Zealand populations and biological mortality rates. To answer this question properly would require an extensive modelling of both populations and include some complex biological interactions. However, it is useful to make first-order estimates of whether $8 \%$ probability is high enough to support west coast New Zealand populations under an assumption that the Australian and New Zealand populations are the same size. We do this by back-calculating biological survival rates that would allow the populations to be sustained, and argue that if these back-calculated rates are lower than realistic values, then trans-Tasman larval flow is likely to be a viable mechanism to maintain west coast New Zealand lobsters.

If we assume virgin (unfished) populations are stable over long periods of time and have an even male to female ratio, then on average only 2 phyllosomas from each female are required to survive into adulthood and reproduce (i.e. on average each female has to replace herself and 1 male.) If, on average, each female hatches $N$ eggs over a lifetime, and each phyllosoma has a probability (p) of crossing the Tasman Sea, then one can calculate the cumulative survival rate $(s)$ for phyllosomas by noting that $N p s=2$, where $s$ is the cumulative survival rate from hatching to onset of sexual maturity. One can ignore mortality in the adults, since it is absorbed into $N$.

It is safe to assume that on average each Jasus edwardsii female hatches at least 200000 phyllosomas each year over a breeding life of at least $10 \mathrm{yr}$ in virgin stocks (Kensler 1968). With only 2 of 2000000 hatched phyllosomas needing to survive, and a probability of

Table 2. Summary of trans-Tasman Sea travel times

\begin{tabular}{|llccc|}
\hline Species & & $\begin{array}{c}\text { Median } \\
\text { travel time } \\
\text { (d) }\end{array}$ & $\begin{array}{c}\text { \% drifters } \\
\text { arriving in } \\
\text { NZ }\end{array}$ & $\begin{array}{c}\text { \% chance of } \\
\text { arriving in NZ in } \\
<1 \text { larval lifetime }\end{array}$ \\
\hline $\begin{array}{c}\text { Sagmariasus } \\
\text { verreauxi }\end{array}$ & No winds & 838 & 28 & 3 \\
Jasus & No winds & 759 & 19 & 2 \\
edwardsii & Winds & 1009 & 64 & 14 \\
& 1115 & 37 & 8 \\
\hline
\end{tabular}


$8 \%$ that each phyllosoma gets across the Tasman Sea, the population would be maintained provided the biological survival $s$ were $0.0013 \%$ or higher.

This survival rate appears so low that it seems likely that it would be exceeded in nature. However, there are 3 life stages to be considered-from hatching to metamorphosis (i.e. phyllosoma phase), from metamorphosis to settlement (i.e. puerulus phase), and from settlement to the onset of sexual maturity (i.e. juvenile phase) - and the cumulative survival is the product of the survival at each of the 3 phases. One could, for example, obtain a cumulative survival of $\sim 0.0013 \%$ from a $1 \%$ survival of phyllosomas, $2.5 \%$ survival of the pueruli, and $5 \%$ survival of the juveniles.

Estimates of mortality are notoriously problematic and variable, but we believe that survival rates in reality are higher than those above. For example, based on studies of mortality to the end of the 1st yr in Panulirus argus and P. cygnus (Butler et al. 1997, Phillips et al. 2001), and of survival throughout the juvenile phase of Jasus edwardsii (Annala 1979), we believe realistic rates might be more like $10 \%$ for the puerulus phase and $30 \%$ for the juvenile phase. If so, and one accepts $1 \%$ survival of phyllosomas, then in reality $s$ may be about $0.03 \%$, i.e. $24 \times$ higher than the minimum required $0.0013 \%$.

The factor 24 is comfortably large, so much so that we suggest that for virgin fish stocks, the probability of larvae crossing the Tasman Sea during 1 lifetime is high enough that west coast New Zealand populations could be maintained from Australia. However, the main evidence that Australia supports at least some west coast New Zealand Jasus edwardsii is still circumstantial: there is no apparent oceanographic mechanism for entraining west coast New Zealand-hatched phyllosomas; phyllosomas are found all the way across the Tasman Sea; and the Australian and New Zealand populations are genetically homogenous.

Is there an oceanographic reason for the possible differences in genetic structure between Sagmariasus verreauxi and Jasus edwardsii? There is a large body of literature devoted to the question of just how much gene flow is required between 2 populations to maintain genetic diversity (e.g. Futuyma 1998) and while the answers depend on complex parameters such as relative population sizes and the presence of natural selection processes, they tend towards 'not much' rather than 'a lot'. Certainly a lot less larval transport is required to maintain genetic homogeneity than is required to maintain the entire population. If a transTasman survival rate of $8 \%$ is sufficient to maintain $J$. edwardsii populations, it is difficult to imagine that a survival rate of $2 \%$ does not maintain genetic homogeneity for $S$. verreauxi.

Based on these simulations, it appears that larval flow across the Tasman Sea should be sufficient to at least maintain trans-Tasman genetic homogeneity in both species. But if Sagmariasus verreauxi is isolated across the Tasman Sea as suggested by the genetic data, this implies that there is a biological mechanism blocking gene transfer. One such reason may be that for $S$. verreauxi phyllosomas to cross the Tasman Sea within 1 yr, they would have to cross north of the productive STF, and it may be that there is not enough prey to sustain them. Fig. 5 shows mean chlorophyll a levels derived from Coastal Zone Color Scanner (CZCS) satellite, and shows the region of higher productivity along the STF (40 to $45^{\circ} \mathrm{S}$ ). Comparison of this figure with the tracks shown in Fig. 4 suggests that $S$. verreauxi would cross the Tasman Sea in much less productive regions than Jasus edwardsii. There is some evidence to support this hypothesis: $S$. verreauxi phyllosomas have never been reported in the Tasman Sea east of Lord Howe Island (i.e. about $600 \mathrm{~km}$ from the Australian coast; Fig. 1). Since Lord Howe Island is well within 1 yr's drift of their source, this suggests that there is indeed a biological reason for their non-survival.

The results presented here should be regarded as a first attempt at modelling the trans-Tasman larvae problem, and integrat-
Fig. 5. Mean chlorophyll a levels as measured by the Coastal Zone Color Scanner (CZCS). The region of higher productivity along the Subtropical Front (STF) can be seen between 40 and $45^{\circ} \mathrm{S}$ 
ing lobster biology with ocean dynamics. However, most of the biology associated with phyllosomas has been ignored here. In particular, we have not modelled the possible impact of horizontally directed swimming. There is no doubt that off the east coast of New Zealand, Jasus edwardsii pueruli, and possibly latestage phyllosomas, swim to the west or northwest (Chiswell \& Booth 1999). Whether the pueruli actively swim towards the coast, or whether they are genetically programmed to swim westward, is so far unknown. If the latter, then pueruli metamorphosing off the west coast of New Zealand will be less likely to make it to settlement compared to the east coast populations. We have assumed that hatched phyllosomas start from $200 \mathrm{~km}$ offshore, and have not incorporated any coastal processes on the New Zealand side. Further work in this area should include the biological mechanisms not considered here and an assessment of whether they aid or hinder survival.

Acknowledgements. We thank M. Hadfield and M. Bowen for helpful discussions and comments on the manuscript, and 3 anonymous reviewers for their comments. The altimeter products were produced by the CLS Space Oceanography Division as part of the European Union Environment and Climate project AGORA (ENV4-CT9560113) and DUACS (ENV4CT96-0357) with financial support from the CEO programme (Centre for Earth Observation) and Midi-Pyrenees regional council. The CARS ocean climatology was provided by CSIRO, Australia. This work was carried out under the New Zealand Foundation of Research, Science and Technology contract CO 1422.

\section{LITERATURE CITED}

Annala JH (1979) Mortality estimates for the New Zealand rock lobster, Jasus edwardsii. Fish Bull 77:471-480

Annala JH, Sullivan KJ, O'Brien CJ (2001) Report from the mid-year fishery assessment plenary, November 2001: stock assessments and yield estimates. NIWA, Wellington

Black KP (1994) Developments in our knowledge of dispersal on the Great Barrier Reef. In: Sammarco PW, Heron ML (eds) The bio-physics of marine larval dispersal. American Geophysical Union, Washington DC, p 352

Blayo E, Mailly T, Barnier B, Brasseur P, LeProvost C, Molines JM, Verron J (1997) Complementarity of ERS 1 and TOPEX/POSEIDON altimeter data in estimating the ocean circulation: assimilation into a model of the North Atlantic. J Geophys Res 102:18573-18584

Booth JD (1986) Recruitment of Packhorse Rock Lobster Jasus verreauxi in New Zealand. Can J Fish Aquat Sci 43: $2212-2220$

Booth JD (2003) Early life history, recruitment processes and settlement of spiny lobsters. Fish Sci (in press)

Booth JD, Breen PA (1992) Stock structure in the New Zealand red rock lobster, Jasus edwardsii. Report No. 92/20, Ministry of Agriculture and Fisheries, Wellington

Booth JD, Ovenden JR (2000) Distribution of Jasus spp. (Decapoda: Palinuridae) phyllosomas in southern waters: implications for larval recruitment. Mar Ecol Prog Ser 200: 241-255
Booth JD, Phillips BF (1994) Early life history of spiny lobster. Crustaceana 66:271-294

Booth JD, Stewart RA (1992) Distribution of phyllosoma larvae of the red rock lobster Jasus edwardsii off the east coast of New Zealand in relation to the oceanography. In: Hancock DA (ed) Larval biology. Proceedings no. 15, Australian Society for Fish Biology Workshop. Australian Government Publishing Service, Canberra, p 138-148

Booth JD, Street RJ, Smith PJ (1990) Systemic status of the rock lobsters Jasus edwardsii from New Zealand and $J$. novaehollandiae from Australia. NZ J Mar Freshw Res 24: 239-249

Brasher DJ, Ovenden JR, Booth JD, White RWG (1992) Genetic subdivision of Australian and New Zealand populations of Jasus verreauxi (Decapodia: Palinuridae)preliminary evidence from the mitochondrial genome. NZ J Mar Freshw Res 26:53-58

Butler MJ, Herrnkind WF, Hunt JH (1997) Factors affecting the recruitment of juvenile Caribbean spiny lobsters dwelling in macroalgae. Bull Mar Sci 61:3-19

Chiswell SM, Booth JD (1999) Rock lobster Jasus edwardsii larval retention by the Wairarapa Eddy off New Zealand. Mar Ecol Prog Ser 183:227-240

Dunn JR, Ridgway KR (2002) Mapping ocean properties in regions of complex topography. Deep-Sea Res I 49: 591-604

Fu LL, Christensen EJ, Yamarone CA, Lefebvre M, Menard Y, Dorrer M, Escudier P (1994) Topex/Poseidon mission overview. J Geophys Res 99:24369-24381

Futuyma DJ (1998) Evolutionary biology. Sinauer, Sunderland, MA

Kelly LG (1967) Handbook of numerical methods and applications. Addison-Wesley, Reading, MA

Kensler CB (1968) Notes on fecundity in the marine spiny lobster Jasus edwardsii (Hutton) (Crustacea: Decapoda: Palinuridae). NZ J Mar Freshw Res 2:81-89

Mitchum GT (1994) Comparison of TOPEX sea surface heights and tide gauge sea levels. J Geophys Res 99: 24541-24553

Ovenden JR, Brasher DJ, White RWG (1992) Mitochondrial DNA analyses of the red rock lobster Jasus edwardsii supports an apparent absence of population subdivision throughout Australasia. Mar Biol 112:319-326

Phillips BF, Chubb CF, Melville-Smith R (2000) The status of Australia's rock lobster fisheries. In: Phillips BF, Kittaka J (eds) Spiny lobsters fisheries and management. Blackwell Scientific Publications, Oxford, p 45-77

Phillips BF, Melville-Smith R, Cheng YW, Caputi N, Hung TC, Thomson A (2001) Aspects of puerulus settlement and the question of biological neutrality in the western rock lobster fishery. Report no. 98/302, Fisheries Research and Development Corporation Project, Canberra

Pollard RT, Millard RC (1970) Comparison between observed and simulated wind-generated inertial oscillations. DeepSea Res II 17:813-821

Pond S, Pickard GL (1978) Introductory dynamical oceanography. Pergamon Press, Oxford

Ridgway KR, Dunn JR, Wilkin JL (2002) Ocean interpolation by 4-dimensional weighted least squares-application to the waters around Australasia. J Atmos Oceanic Tech 19(9):1357-1375

Sprintall J, Roemmich D, Stanton B, Bailey R (1995) Regional climate variability and ocean heat transport in the southwest Pacific Ocean. J Geophys Res 100:15865-15871

Stanton BR (1981) An oceanographic survey of the Tasman Front. NZ J Mar Freshw Res 15:289-297

Submitted: June 26, 2002; Accepted: October 22, 2002

Proofs received from author(s): January 17, 2003 